ISSN: 1641-4713; e-ISSN: 2081-1160

DOI: https://doi.org/10.36551/2081-1160.2021.27.133-157

\title{
Dialéctica víctima-perpetrador como causación de la novela Con sangre de hermanos
}

\author{
Victim-perpetrator dialectics as causation in the novel Con sangre \\ de hermanos
}

\author{
David Francisco Nani \\ Investigador independiente \\ ORCID: https://orcid.org/0000-0002-8684-9616 \\ E-mail: davidfrancisconani@gmail.com
}

Recepción: 16.08 .2020

Aprobación: 23.04.2021

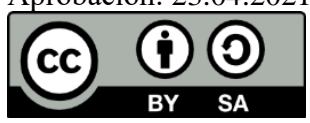

Resumen: Este escrito trata acerca de la novela Con sangre de hermanos. Demuestra cómo los personajes primero son profundamente afectados por la represión de la Guardia Nacional somocista. Luego ellos afrontan los traumas y las disociaciones de una forma no ética: asesinando y persiguiendo a los miembros de la oposición. Más aun, los sandinistas parecen anuentes a ser "zonas grises" y a sacrificarse a sí mismos por el partido izquierdista. Culmina el escrito con un FSLN (Frente Sandinista de Liberación Nacional) alimentado por los crímenes y las traiciones contra sus propios miembros. En conclusión, tenemos que el libro se estructura como una novela de perpetradores.

Palabras clave: perpetradores, guerras civiles nicaragüenses, FSLN, violencia política, dictaduras, trauma, comunismo.

Abstract: This paper deals with the novel Con sangre de hermanos. It demonstrates how the charac-
ters firstly become deeply affected by Somoza's National Guard repression. Then they cope with those
traumas and dissociations in an unethical way: killing and persecuting opposition members. More-
over, Sandinistas look able to be in the "grey area" and to sacrifice themselves for the leftist party.
It ends up with an FSLN (Sandinista National Liberation Front) strengthened by the crimes and
betrayals to its own members. It concludes that this book has been structured as a perpetrator novel.

Keywords: perpetrators, Nicaraguan civil wars, FSLN, political violence, dictatorships, trauma, communism. 


\section{INTRODUCCIÓN}

Rompiendo los moldes de la exclusividad de la filología, la literatura ha sido adoptada como objeto de análisis por los estudios culturales, un esfuerzo interdisciplinario surgido a finales del siglo XX. Y en específico, hablamos aquí de la incursión de los estudios de la memoria en tanto forma de ingreso para el abordaje de cuentos, novelas y demás creaciones ficcionales. Dicho ámbito de trabajo suele abordar temáticas relativas al Holocausto, y en general cercanas a procesos de intensa violencia política en diferentes países del mundo.

El escrito adopta un reciente campo particular de los estudios de la memoria, como lo es el de los perpetradores. Y efectúa dicho esfuerzo en el análisis de una novela centroamericana, Con sangre de hermanos (Aguirre, 2011). Esto tiene justificación en dos diferentes argumentos. Primero, el interés de abordar un libro reciente desde un marco innovador. En segundo lugar, volver la mirada hacia la literatura política de América Central.

¿Cómo se estructura el presente escrito? El texto aborda el tema de los personajes de Gregorio (nombrado Goyo) y Gerardo en tanto ubicados en una dialéctica de víctimas y perpetradores. En términos de la Poética de Aristóteles (1999) hablaríamos del nudo, aquella cuestión dramática y conflictiva que funge de aspecto medular de la composición. El nudo de Con sangre de hermanos se desarrolla en términos de víctimas-perpetradores.

Para no trastocar el debido orden expositivo, digamos que estos dos personajes, centrales en la novela, inician siendo víctimas de la dictadura de Anastasio Somoza, para luego erigirse en miembros de los aparatos represores del FSLN. Termina, caso de Goyo, siendo objeto de un brutal engaño por parte de sus exjefes, esto en la Nicaragua de Arnoldo Alemán. Entonces proponemos que las biografías de ambos personajes (en lo relativo a su praxis política) oscilan entre ser víctimas y el ubicarse como perpetradores. Más aun, planteamos dicha dialéctica como eje fundamental de la novela.

\section{Hipótesis}

La novela Con sangre de hermanos se estructura en la dialéctica víctimaperpetrador.

Para comprobar dicha hipótesis, la obra procede a un capítulo donde se reconstruye el tema de los perpetradores. Acto seguido, pasa a una aplicación de lo anterior a la novela, trayendo a colación fragmentos atinentes, es decir, segmentos narrativos mediante los cuales se prueban enunciados. 


\section{2. ¿QUÉ ENTENDEMOS POR LA DIALÉCTICA VÍCTIMA-PERPETRADOR?}

En el presente apartado se aclara el sentido de este concepto. De acuerdo con Critchell et al. (2017) ${ }^{1}$ el término tiene raíces en la jerga jurídica y ética y alude a aquellos que cargan sucesos considerados como malvados y no justificables éticamente, en un juicio realizado por otros sujetos. Los acusados de ser perpetradores tienden a racionalizar y justificar sus acciones (Critchell et al., 2017). El proceso de la memoria dista de la simpleza:

In post-war societies, former conflict parties are likely to hold views on the past that stand diametrically opposed to each other. Likewise, in countries emerging from repressive rule, perpetrators and victims will express antagonistic opinions about the previous period. Since these groups usually attempt to influence public opinion in their favor, their memories can be manipulative. (Bothmann, 2015, p. 48) ${ }^{2}$

De esto tenemos que los perpetradores no siempre son vistos como tales y no pocas argucias suelen ser tejidas en torno a estas figuras. La politización de los casos puede ser eventualmente un factor interviniente. La memoria se convierte en un terreno en disputa. Siempre en América Central, el caso de Guatemala revela que: "The battle for memory is not waged against forgetting, but against the different memories different social groups understand as truth" (Hatcher, 2018, p. 107) ${ }^{3}$. Con esta frase, Hatcher se refiere a las discusiones en torno a la rememoración de las víctimas de la guerra civil guatemalteca.

Además, debido a complejas tramas sociales, la construcción de la memoria puede decantar en olvidos o incluso en justificaciones. Por su parte, Nygren (2003) nos habla de otro fenómeno. En Nicaragua no se juzgó a los criminales políticos para evitar la desestabilización en la frágil etapa de cambio, pues juicios políticamente investidos acarreaban dicha posibilidad. Sin embargo, justamente la acreditación de los ultrajes a los derechos humanos es vital para que las personas se recuperen y para evitar repeticiones cíclicas de los procesos de violencia. Así, vemos que no siempre se llevan a la práctica formas de reparar las persecuciones y los asesinatos por razones políticas, ni tampoco todos convergen a lo interno de los países acerca de tal necesidad.

\footnotetext{
${ }^{1}$ Este artículo resulta basal del presente estudio porque es el texto de apertura de una revista especializada en el tema de los perpetradores.

2 "En las sociedades de posguerra, las anteriores partes en conflicto son tendientes a defender visiones del pasado diametralmente opuestas una respecto a la otra. De tal forma, en países emergentes de mandatos represivos, perpetradores y víctimas expresarán opiniones antagónicas acerca del periodo previo. Debido a que estos grupos usualmente intentan influenciar la opinión pública a su favor, las memorias pueden ser manipulativas" (Bothmann, 2015, p. 48, traducción del autor).

3 "La batalla por la memoria no se libra contra el olvido, sino contra las diferentes memorias sociales que los grupos entienden como verdad" (Hatcher, 2018, p. 107, traducción del autor).
} 
Por consiguiente, detrás de los actos más directos de violencia política, según el consenso dominante, un concepto inconsciente de perpetrador conduce al silencio en otros eventos que en virtud de lo primero sí deben encasillarse como perpetraciones. Así, actos de violencia política pueden discutirse como ejemplos de perpetración aun cuando no se reconozcan como tales en las sociedades donde acontecieron (Critchell et. al., 2017).

Los perpetradores son quienes cometen actos de violencia masiva en contra de civiles, y por perpetración se entiende el proceso en el cual son cometidos actos de una violencia atentatoria contra masas. De acuerdo con Critchell et. al. (2017), hay tres niveles analíticos para encasillar a los perpetradores:

- Macro: se refiere a los arquitectos de alta jerarquía, tomadores de decisión que impulsan los crímenes.

- Meso: relativo a quienes se ubican inmediatamente debajo del nivel anterior. Dividen tareas y organizan los actos de violencia. Son élites de mediano poder encargadas de lo administrativo de la represión.

- $\quad$ Micro: es el estrato más bajo. Se refiere a quienes de modo directo o indirecto cometen los crímenes.

Los niveles más altos son condición necesaria, pues sin éstos y sin la radicalización que llevan a cabo la concepción de las violencias del estrato meso no podría ser una realidad, y los múltiples ejecutores del nivel bajo no podrían asesinar a un incontable número de personas en situaciones micro. Sin embargo, también puede acontecer que la radicalización de los niveles inferiores conduzca a que los estamentos macro sancionen la extrema violencia. En todo caso, puede notarse una interdependencia de niveles (Critchell et. al., 2017). El proceso dista así de la unidireccionalidad o la simpleza.

Por otra parte, las dinámicas entre víctimas y perpetradores pueden mutar en el desarrollo del fenómeno: "Perpetrators can become victims; victims can become perpetrators; and 'bystanders' or 'third parties' can become either' (Critchell et. al., 2017, p. 13) ${ }^{4}$. Entonces el proceso no es estático y puede haber cambios en los roles. Esto incluso puede ser de mayor agudeza. Hinton (2016), citado por Bouwknegt (2017), habla de un perpetrador camboyano del Khmer Rouge de características camaleónicas, que pasó, entre muchas otras transformaciones, de víctima a victimario y viceversa.

\footnotetext{
4 "Los perpetradores pueden convertirse en víctimas; las víctimas pueden convertirse en perpetradores; y los 'espectadores' o 'terceras partes' pueden convertirse en cualquiera de los dos" (Critchell et. al., 2017, p. 13, traducción del autor).
} 
¿Tenemos casos similares en otros países del Sur Global? La respuesta es afirmativa. Maringira (2016) aporta un ejemplo africano. Este experto escribió un artículo donde nos expone lo siguiente:

While studies on soldiers who leave the army have focused on them as perpetrators of political violence in war and peace, little is known about the ways in which soldiers have been subjected to violence. This paper examines the ways in which Zimbabwe National Army deserters who are currently in exile in South Africa experienced politically inspired violence in the army barracks and the ways in which they mediate and reify it through the image of the "torn underwear." (Maringira, 2016, p. 429)

Así, las instituciones represoras no ejercen su violencia política de modo único en contra de civiles, los propios integrantes de los aparatos castrenses pueden sufrir agresiones en el marco de la perpetración de crímenes políticos.

Entonces, ¿Cómo entender al perpetrador? Morag (2018), comentando a Morag (2013), establece rasgos de importancia para responder a la pregunta:

Recognizing a current shift in interest from the trauma suffered by victims, which is mostly a psychological trauma, to that suffered by perpetrators, which is first and foremost an ethical trauma, the book breaks over one hundred years of repression of the abhorrent figure of the perpetrator in psychoanalysis and trauma literatures (and in cinema trauma scholarship). The direct result of the new style of war, the new paradigm stages the trauma of the soldier turned perpetrator through a lethal clash with a civilian in an atrocity-producing situation. (Morag, 2018, p. 17) ${ }^{6}$

Por consiguiente, contamos aquí con un primer esbozo, pues en la figura del perpetrador converge una situación de víctima con la de agresor, mediando una forma particular de manejo de los traumas sufridos, una en la cual quien los sufre opta por ejercer la beligerancia en contra de otros sujetos. Esto debe ser complementado para un mejor entendimiento:

I suggest that though the perpetrator era's new phenomenon proposes a totally new conception, adhering to both subject position and action as the dimensions of perpetratorhood

\footnotetext{
5 "Mientras los estudios sobre los soldados que dejaron el ejército han focalizado en éstos como perpetradores de violencia política en guerra y paz, poco es conocido acerca de los modos en las cuales soldados han sido sujetos a violencia. Este articulo examina las formas en las cuales soldados del Ejército Nacional de Zimbabue quienes están actualmente exiliados en Sudáfrica experimentaron violencia políticamente inspirada en las barracas del ejército y las maneras en las cuales ellos lo median y cosifican a través de la imagen de la 'ropa interior rasgada" (Maringira, 2016, p. 429, traducción del autor).

6 "Reconociendo un giro actual en el interés desde el trauma sufrido por las víctimas, el cual es mayormente un trauma psicológico, al que sufrieron los perpetradores, el cual es primero y principalmente un trauma ético, el libro hace una ruptura contra cien años de represión de la abominable figura del perpetrador en las literaturas del psicoanálisis y del trauma (y en los estudios académicos del cine). El resultado directo del nuevo estilo de guerra, el nuevo paradigma escenifica el trauma del soldado convertido en perpetrador a través del enfrentamiento letal con un civil en una situación productora de atrocidades" (Morag, 2018, p. 17, traducción del autor).
} 
points to the context as a vital, third, factor, with the ethics it entails. The new evaluation of the ethical dimensions in human action being comprehended in terms of the new war's dynamics demands that society recognize that it sent the soldiers-who-becameperpetrators into these atrocious situations. (Morag, 2018, p. 17) ${ }^{7}$

El texto nos habla de sujetos, acciones y contextos. De tal manera, respecto a las dos primeras dimensiones, debemos acotar el escenario psicológico en sus elementos claves. Así, si hablamos de la previa calidad de víctima del perpetrador, derivada luego en violencia en contra de otros por decisión de este, suponemos de suyo un asunto ético.

En una incardinación histórica y social en la que la persona ha sido sujeta a traumas (por ejemplo, merced al entrenamiento militar), este individuo decide tomar esa angustia y ese dolor como "argumento", causándolos a otros sujetos. Deducimos que puede mediar la proyección u otros mecanismos de defensa. Y el asunto es dilema ético no solo para el perpetrador, sino también para los otros muchos actores del contexto. Morag (2018) subraya el cuestionamiento moral para las sociedades responsables de enviar soldados devenidos en perpetradores e involucrados en actos atroces.

¿Cómo entendemos ese sustrato psicológico que antecede la perpetración? ¿Cómo se relacionan el perpetrador y el trauma? Consultando la obra de un psiquiatra experto en temas de guerra y violencia política, traído a colación por Morag (2018), retomamos varios aspectos:

- $\quad$ Acontece en el perpetrador un proceso disociativo, donde se desarrolla un segundo "sí-mismo" adaptado al contexto donde se da la comisión de actos violentos, mediante un "sub-yo" de comportamiento autónomo, que se suma a prácticas que en otras circunstancias hallaría aberrantes (Lifton, 2006).

- Lifton (2005) nos habla de los sobrevivientes de carácter inmediato y de aquellos cuya índole es más distante. Los primeros han tenido una relación directa con la muerte o han sufrido pérdidas de familiares, y se caracterizan por sufrir reacciones viscerales, sus psiques han sido debilitadas y deben luchar por reconstruir su self. Aquellos cuyo encuentro con el trauma fue más distante tienen una afectación menos elemental, pero pueden desarrollar respuestas muy pasionales, definiendo éstas como un

\footnotetext{
7 "Sugiero que, aunque el nuevo fenómeno de la era del perpetrador propone una concepción totalmente nueva, el adherirse a ambas posiciones del sujeto y de la acción como las dimensiones de la perpetración apunta al contexto como un factor tercero y vital, con la ética que esto involucra. La nueva evaluación de las dimensiones éticas en la acción humana comprendida en términos de las dinámicas de la nueva guerra demanda que la sociedad reconozca que envió a los soldados-que-se-convirtieron-perpetradores a estas situaciones atroces" (Morag, 2018, p. 17, ttraducción del autor).
} 
sentimiento de miedo tanto personal como colectivo y de humillación del orgullo patrio. A las claras el sufrimiento no parece ser el mismo y los "pesos éticos" de las actuaciones de cada tipo serán por tanto distintos.

- $\quad$ Ubicándose en el contexto de las campañas militares estadounidenses en Vietnam e Irak, Lifton (2006) habla de que los soldados, pese a su superioridad bélica, se sentían vulnerables en un entorno hostil, a lo cual se suma la dificultad para reconocer a las tropas enemigas, lo cual decantó en la frustración de los mandos superiores. Todo esto se tradujo, caso de Irak, en igualar el concepto de "iraquí" con el de "terrorista".

- Asimismo, se establece un sentimiento de pena emparejado con la ira, producido por la muerte de los colegas merced a las acciones de enemigos "invisibles" (Lifton, 2006). Al respecto Lifton (2005) afirma que, frente a las experiencias de trauma, algunos sujetos se sanan al hallar sabiduría de los eventos sufridos, pero otros se decantan por la agresión y la guerra. Siempre en línea con el pensamiento de Morag (2018), tenemos que Lifton (2006) de ninguna manera justifica éticamente las atrocidades de los perpetradores. Al respecto establece: "To be sure, individual soldiers and civilians who participated in it are accountable for their behavior, even under such pressured conditions" (Lifton, 2006) ${ }^{8}$. Por tanto, no se trata de legitimar psicológicamente los actos de extrema violencia política, sino de proponer un sujeto que hace un manejo determinado (criminal) de sus emociones. Sin embargo, el autor habla de que la mayor responsabilidad la tienen los mandos más altos.

Vemos al perpetrador como un sujeto con una doble faceta, pues por un lado es víctima del orden social (miembro de un ejército), pero por otro ejecutor de atrocidades contra personas a las cuales nunca conoció y que nada hicieron en su contra ni de su país. Al respecto, Critchell et. al. (2017) mencionan, pero no explican, el concepto de "zonas grises". Morag (2018) aduce que la idea fue producida en el marco de los estudios sobre el Holocausto. Porque el término "zona gris" resulta de suma relevancia para entender la situación socioemocional de muchos perpetradores, y para tener una explicación más integradora del fenómeno.

Levi, un judío italiano sobreviviente y analista de Auschwitz, nos habla de que a lo interno de los campos de concentración las relaciones humanas no podían reducirse a un bloque de persecutores y otro de víctimas. Quienes ingresaban eran sometidos a tratos humillantes no solo por las tropas nazis, sino por las propias víctimas. Al respecto es aportada una descripción: “...to find

8 "Con seguridad, los individuos soldados y civiles que participaron en esta son responsables por sus conductas, incluso bajo condiciones de suma presión” (Lifton, 2006, traducción del autor). 
compensation at his expense, to build for itself and at his expense a figure of a lower rank on whom to discharge the burden of the offenses received from above" (Levi, 1989, p. 40) ${ }^{9}$. De tal manera, en el proceso de destrucción de la subjetividad del recién ingresado los propios internos desempeñaban un rol negativo para con éste, aun cuando compartían su estado de víctimas (Levi, 1989).

Más allá de esto, hubo un híbrido de funcionario-víctima, prisioneros del campo al servicio de los nazis: era la zona gris, donde amo y sirviente convergían en algunos aspectos y divergían en otros al mismo tiempo. Las motivaciones eran variadas: cobardía, cálculo, deseo de poder (aun cuando fuera circunscrito), temor, afinidad ideológica, privilegios (aunque fuesen nimios), entre otros (Levi, 1989). Las zonas grises no tuvieron óbito con el fin del Holocausto y la derrota de los nazis; por el contrario, según Critchell et. al. (2017) éstas han proliferado e incluyen procesos muy recientes en distintas partes del mundo.

Y Esparza (2018) ubica el concepto en el marco de América Latina, pues nos habla del militar como alguien que destruye sus propias raíces. De esto se tiene:

Within this dynamic, it is imperative to consider how colonial legacies and extreme forms of discrimination and poverty help shape what groups are called to join the state's army - even when serving goes against their own political, racial, ethnic, and class prerogatives. (Esparza, 2018, p. 23) 10

Por tanto, ubicamos en lo dicho sobre todo a los niveles meso y micro, en virtud de ser sujetos que de antemano estaban en una profunda desventaja social, pero son luego reclutados por los aparatos represivos para ejercer la violencia contra quienes son como ellos ${ }^{11}$. Debido a lo anterior, se fortalecen las dinámicas de exclusión que los han afectado tanto a ellos como a sus sectores sociales. Esparza (2018) expone sobre el caso de Guatemala, en el cual individuos de comunidades mayas cometieron atrocidades contra sus propios vecinos, bajo la égida del ejército y con la amenaza de duro castigo en caso de desobedecerle.

\footnotetext{
9 “...para hallar compensación a sus expensas, para construir para sí mismo y a sus expensas una figura de rango más bajo sobre quien descargar el peso de las ofensas recibidas desde arriba" (Levi, 1989 , p. 40, traducción del autor).

10 "Dentro de esta dinámica, es imperativo considerar cómo los legados coloniales y las formas extremas de discriminación y pobreza ayudan a moldear qué grupos resultan llamados a unirse al ejército del estado, incluso cuando servirle vaya en contra de sus propias prerrogativas políticas, raciales, étnicas y de clase" (Esparza, 2018, p. 23, traducción del autor).

${ }^{11}$ No puede excluirse la posibilidad de perpetradores macro que en un pasado sufrieron de dichas violencias; en América Latina y África hay casos de dictadores provenientes de sectores empobrecidos y discriminados que luego, al tomar el poder, pasan a ser victimarios de países enteros.
} 


\section{LA NOVELA CON SANGRE DE HERMANOS COMO UN CASO DE LA DINÁMICA VÍCTIMA-PERPETRADOR}

Para la argumentación del apartado, procedemos a una reconstrucción de la narrativa. Primero describimos los hechos ficcionales relatados en el libro y acto seguido aplicamos los conceptos del capítulo anterior, a fin de corroborar o refutar la hipótesis. Para una mayor claridad, recurrimos a subtítulos donde se da cuenta de las distintas etapas de los personajes.

\subsection{Víctimas de Somoza}

Los hechos de la novela pueden dividirse en tres partes, a guisa del escrito presente. En principio tenemos la época anterior al recrudecimiento de las acciones del FSLN contra la dictadura somocista. En este intervalo Goyo, Gerardo y otros muchos nicaragüenses son víctimas del ejército regular, llamado Guardia Nacional. Un primer elemento lo representa el tema familiar, la persecución y la prisión sufridas por los padres de los protagonistas. En la página 20 se habla sobre las detenciones del padre de Gerardo por motivos estrictamente políticos. Y luego se habla de su encarcelamiento: "Los rasgos que ciertos apuntes de Gerardo esbozan sobre su padre, son los de un hombre alto y orgulloso, a quien era difícil imaginar sometido a la humillación" (Aguirre, 2011, p. 30). Vemos una impronta traumática en el personaje desde sus edades tempranas, causada por procesos represivos. Gregorio o Goyo sufre idéntico problema: "Señaló sin ningún temor hacia los torreones del fortín, recordándoles luego, como para confortarlos, que su propio padre también estaba ahí encerrado" (Aguirre, 2011, p. 34). Entonces ellos padecen de cerca la represión de Somoza.

Más aun, se insiste en las repercusiones emocionales de los asuntos políticos:

Entonces Gerardo no lograba entender por qué aquella anécdota aparentemente insulsa hiciera reír tanto a su amigo, pero el aparente buen humor de Gregorio ayudó a que la idea triste de saber presos a sus padres, no les pesara tanto aquella tarde. (Aguirre, 2011, p. 34)

Estas situaciones son un primer elemento traumático para los jóvenes, futuros guerrilleros, cuyo mundo social sin embargo no siempre estuvo vinculado al sandinismo ni a los movimientos sociales. Antes se habla de cómo ambos adolescentes, pero sobre todo Gerardo, se hunden en la, por así llamarla, "cultura alternativa urbana" de Managua, un mundo de drogas, prostitutas y rock and roll. A este escenario irrumpe la policía y tras una gresca en una fiesta usa sus armas: "En la calle la quinceañera lloraba, frotándose el vestido manchado con la sangre de su hermano herido, mientras los vecinos pedian ambulancias y la madre 
reprendía a gritos a los guardias y llamaba asesino al coronel Cordero Gómez" (Aguirre, 2011, p. 49, cursiva en el original). La continuación de la violencia estatal resulta ostensible y los personajes son testigos presenciales de los hechos.

Pero luego de la politización de los adolescentes la hostilidad se agrava en sumo grado. En la novela tanto Gerardo como su hermano se adhieren a la causa revolucionaria, pero el segundo muere en combate. El suceso tiene consecuencias profundas:

Desde entonces empecé a cultivar interiormente ese raro sentimiento, mezcla de soledad, furia, solidaridad y remordimiento, que no sabía cómo definir y a veces no podía controlar. Un sentimiento que no recordaba haber percibido nunca antes, pero que desde ese día siempre me acompañaba. A veces me parecía que era precisamente ese sentimiento el que me impedía con frecuencia tener una perspectiva clara de las cosas que sucedían a mi alrededor. Por eso trataba de sobreponerme a él a toda costa. (Aguirre, 2011, p. 96, cursiva en el original)

Ya antes, en las páginas 45 y 46 se habla de que a muchos de los compañeros de juerga él los vería fallecer asesinados luego. Y en la página 56 se habla de que la policía disparó a dos vecinas (matando a una), culateó a la madre de Gerardo y también a Goyo, a quién además lanzaron un carro, todo esto tras una marcha (Aguirre, 2011).

El expediente de violencias alimenta poco a poco los deseos de revolución. En el relato el personaje Gerardo recibe de Goyo la indicación del sitio donde se hallaba preso su padre, lo cual resuelve disponiéndose a combatir. En la página 115 nos habla de que Gerardo se hallaba consternado por el asesinato en batalla de su hermano y en disposición de luchar por el proceso revolucionario (Aguirre, 2011).

Se aduce el impacto en la memoria de los muertos en la guerra contra Somoza:

Y fue entonces cuando también empezó a abrigar la certeza, que en adelante siempre lo acompañó, acerca de la rotunda inalterabilidad del pasado. Supo desde entonces que los recuerdos de aquella guerra recién concluida, la memoria de tantos hermanos muertos, permanecería siempre intacta. (Aguirre, 2011, p. 121)

Dado el fragmento citado y anteriores, deducimos que tanto Gerardo como Goyo son sobrevivientes de carácter inmediato, sufriendo de reacciones de naturaleza visceral, así como de un debilitamiento psicológico. En lo sucedáneo veremos cómo en especial el segundo personaje reacciona con suma violencia frente a los eventos políticos.

Pero según veremos adelante, la ecuación incluye otros factores que sustituyen el proyecto político "emancipador" (si es que lo hubo, este punto se reto- 
ma al final del capítulo dada su índole conclusiva) por la perpetración de crímenes. Porque ante la traumática muerte de colegas, los sandinistas resuelven su conflicto psicológico asesinando a otros, sin mayores reparos en cuanto a si estas personas de veras fueron parte de la Guardia Nacional de Somoza o de la contra. Tal proceso coincide con lo dicho por Lifton (2006).

A las claras el tema no solo radica en lo psicológico, sino también en lo ético. Y podemos distinguir una línea argumentativa en la novela, que inicia con los traumas padecidos por la dictadura de Somoza, responsable de una fuerte impronta emocional en los personajes. Y prosigue con la resolución de los conflictos psíquicos acarreados mediante una vía: la de convertirse en ejecutores de nuevas violencias contra civiles.

\subsection{Perpetradores al servicio del FSLN}

En esta categoría descansa el nudo de eventos narrados. Siguiendo un mismo hilo conductor (según se vio era resarcir la memoria de las víctimas), vemos una degeneración creciente en las acciones de los personajes. Tenemos aquí el inicio de los perpetradores ya desde la etapa última del alzamiento contra Somoza. Y se prolonga en la mayor parte de la obra. Una cita resulta diáfana para comprender el esquema de mundo de Goyo:

Para él, lo verdaderamente esencial de las posibles consecuencias de aquella orden suicida, era que no iba a destruirse solo. Su inmolación, aunque en cierto modo generosa y despreciativa de sí misma, sería también despreciativa de las voluntades ajenas, sería totalmente indiferente ante el destino de sus semejantes. (Aguirre, 2011, p. 61)

El fragmento sucede a la narración de que Gregorio se iba a unir a un ataque suicida. Resume en buena medida la sensibilidad del personaje. Pero ¿cuál es la causa?

Pero la búsqueda de esa liberación, al parecer debía pasar por una especie de esclavización provisional que a Goyo lo obligaba además a convertirse en verdugo de sus adversarios, en maestro de las técnicas de aniquilamiento, en el terror de sus enemigos, pero también de sus amigos; en fin, en un hombre temido por moros y cristianos. Ahora se daba cuenta de que Goyo y sus compañeros compartían una especie de rencor ritual, un odio colectivo alimentado por tantos años de guerra. Entonces le preguntó si no creía que, en el fondo, con sus acciones se había vuelto contra sus propios orígenes como revolucionario...

-En la revolución y en la guerra, señorita, se aprende a no pensar en asuntos morales. La moral que debe prevalecer es la moral del vencedor. Aquí prevalece la nuestra, la moral revolucionaria que emana de los fusiles empuñados por el pueblo. (Aguirre, 2011, pp. 243-244) 
Ese resentimiento forma parte fundante de las acciones de Goyo, constituye un eje discursivo. ¿A qué se debe? En la novela encontramos pistas. Antes resaltamos que el fragmento evidencia una renuncia a la ética, el personaje se despliega por las arenas de la eficacia política en una especie de realpolitik barbarizada. Esta renuncia a la ética en nombre de la victoria ha sido postulada por otros revolucionarios anteriores, trayendo consigo grandes problemas. Según Camus (2008), cuando la revolución representa el único valor, deja de haber derechos, pues solo hay deberes y luego, por un trastrueque, en nombre de esos deberes, se toma la totalidad de los derechos. La eficacia en pos del triunfo de unos principios se convierte en la única pauta rectora del comportamiento. Goyo asume dicho patrón del pensar y del actuar como resolución de sus traumas.

Esto concuerda con las definiciones dichas en el segundo capítulo: el perpetrador afronta un trauma ético, derivado de un manejo particular de su antecedente vital y su situación psicológica, manejo en el cual se autoconcede el derecho de asesinar y perseguir a otros seres humanos. Las ansias bélicas hallan su raison d'être en el recuerdo de las guerras, con el cual se alimentan nuevas animosidades y odios:

Puede parecer extraño y hasta paradójico, lo sé, pero la retórica del triunfo sandinista, con su constante y a veces desmesurada exaltación de los muertos, de los héroes caídos durante más de cincuenta años de lucha, nos hacian sentir - pues aquel sentimiento de nostalgia por la guerra invadió también el ánimo de millares de jóvenes en Nicaraguacierto desprecio por la muerte. (Aguirre, 2011, p. 154, cursiva en el original)

Vemos entonces la fundamentación de la guerra en la supuesta venganza y en los colegas asesinados. Asimismo, los perpetradores macro alimentan el proceso por la vía ideológica.

Así, para el caso de Goyo el proceso descansa en vengar a los muertos por el somocismo y las fuerzas contrarrevolucionarias (la contra). En la página 222 se lee que ante los cadáveres de militantes sandinistas muertos en la guerra interna promete implacabilidad y nula tolerancia hacia sus enemigos. Y aduce haber sido testigo de la guerra con la contra:

Usted no sabe lo que es ver a un muchacho de esos perder una pierna por una mina, y que en medio de las balas no grite ni se queje, y que te diga: "no hay falla jefe, cúbrase, no hay falla". Usted no sabe lo que es ver a esos muchachos durmiendo con sus muertos... (Aguirre, 2011, p. 246)

Esto incide en los traumas del personaje, quien a su vez utiliza el recuerdo para convertirse en perpetrador de nuevos vejámenes. Recordemos que para Lifton (2006) la guerra irregular puede disparar los casos de perpetradores (casos de Irak y Vietnam). En la obra vemos algo parecido: a fin de cuentas, la contra 
nicaragüense operaba bajo el formato de guerra de guerrillas (como las insurgencias vietnamita e iraquí). Sobre esto se tienen las palabras de Leonardo, otro combatiente sandinista: "Los muertos pesan siempre más que los heridos, sobre todo cuando uno no ha podido descargar el odio, los deseos de venganza, y hay que volver con las manos vacias, sin haber podido matar a ningún hijo de puta" (Aguirre, 2011, p. 152, cursiva en el original). Ese odio, alimentado por la frustración, será descargado luego sobre todo aquel que critique al FSLN, en una lógica dicotómica totalitaria.

Podemos deducir de esta constante alusión a la venganza y a una "violencia redentora" una particular construcción de la memoria. Así, a nivel colectivo se emplean las rememoraciones de las victimas presentes y pasadas para justificar la política violenta, dictatorial y agresiva del FSLN. Porque ambos personajes, Gregorio y Gerardo, presenciaron crímenes y violencias, pero Goyo se decanta por la hostilidad y la agresión hacia otros. Todo esto concuerda con lo dicho por Lifton (2006), pues vemos que merced a situaciones en extremo amenazantes, los sujetos optan por la violencia contra otros, sin reparos en quienes son.

También hallamos rasgos parecidos al efecto de "sub-yo" descrito por Lifton (2006). Porque se habla de procesos disociativos en los que los sujetos dividen su self. Tanto Goyo como Gerardo experimentan dudas acerca del proceso revolucionario, pero las vías de resolución son muy distintas. De Gerardo nos ocupamos adelante. Goyo resuelve el asunto mediante el fanatismo: “...siempre terminaba por prevalecer el instinto de adhesión que juzgaba implícito a la causa rebelde, a la enorme cruzada que acabó por contagiar al país entero" (Aguirre, 2011, p. 93). Después se dice:

Sin embargo, tampoco parecía tener plena conciencia de que ese juicio que lo convencía de la necesidad de su plena adhesión a la causa y lo mantenía erguido en medio del peligro, era el mismo que también lo hacía adherirse a una parte desconocida de sí mismo a la que temía enfrentar y lo hacía dudar. (Aguirre, 2011, p. 94)

Vemos ciertamente un yo dividido, una parte de Goyo permanece oculta (¿la que aún no supera los traumas de la violencia?), a esa parte oculta se adhiere su juicio obcecado acerca del FSLN, una posible forma de manejar su trauma (¿tapa ese juicio la evaluación ética y la eventual culpa?). El juicio parece partir de la parte "evidente" del yo de Gregorio, la que comete gran violencia (como se evidencia luego), y desplaza al self escondido. La parte oculta podría ser la que, en otras circunstancias, hallaría aborrecibles tales actos, a guisa de la teoría de Lifton (2006). Sin embargo, las emociones no son manejadas para conducir su vida de otro modo, sino que alimentan la llama de la violencia política. 
No obstante, como Goyo nunca se desarrolla en otro contexto, ni se plantea actuar de otra manera, la parte de su self que hallaría deleznable la hostilidad nunca aflora. Tiene sentido, porque Lifton (2006) parte de ejemplos estadounidenses, en los cuales los exsoldados tienen la oportunidad de moverse a otro contexto, uno donde no hay más guerra (su país, Estados Unidos), en cambio Goyo no tiene dicha posibilidad. Lo anterior no da paso a una exención ética del personaje ni mucho menos, porque Gerardo vivió casi las mismas violencias, y sin embargo su disposición hacia la sociedad es otra, porque otras son sus decisiones. Este personaje no tiene por rasgo el fanatismo, sino la duda. Ya desde el triunfo de la revolución el personaje se sentía aquejado por aquel sentimiento:

Entonces me acordé de Goyo, y me pregunté si, al igual que los comandantes, ¿̇no estaría él también siendo presa de la duda, de la incertidumbre, de alguna vacilación ante aquel instante cumbre de la historia? Supuse entonces que, en aquel momento, cada uno de mis compatriotas, de alguna forma, podía estar también interrogándose a sí mismo respecto a la oscura e intrigante nebulosa con que el porvenir se mostraba, justo enfrente de nuestras narices. (Aguirre, 2011, p. 99, cursiva en el original)

Nótese la diferencia entre Goyo y Gerardo, porque el primero en forma reiterada hace patente su obcecación político-ideológica y, sobre todo, su sed de hostilidad y de desquitarse con los opositores de las acciones del somocismo y de la contra. De Gregorio se narra que pretende correr al mismo paso que la historia, en el desarrollo de la novela habrá de develarse el sentido de esa pretensión, equivalente a la renuncia a la libertad en nombre de la supuesta necesidad, presupuesto de otros revolucionarios de otras épocas según Camus (2008). Goyo se percibe bajo la forma de mero instrumento de unos sectores sociales vejados que pasan a "hacer justicia", lo cual en realidad significa ejercer violencia contra otros.

En contraste Gerardo, aun bajo la embriaguez del triunfo contra Somoza, duda; para él, la Nicaragua liberada es campo abierto de decisiones personales y colectivas, no agenda preestablecida. En otras partes vemos esta reiterada actitud del personaje. La contraposición entre Goyo y Gerardo puede compararse relativamente con la planteada por Merleau-Ponty (1957), para quien Marx y el Partido propusieron que la revolución es un principio actuante en las cosas en vez de un grupo de gentes que dudan y un colectivo de dirigentes perplejos. En una alternativa hay reificación de conceptos y superchería; en la segunda, sujetos que aspiran y eligen, y cuyas decisiones tienen un impacto. Por lo respectivo al presente argumento, sírvase leer la página 187, donde el sujeto se muestra dubitativo de asumir su puesto en una institución de inteligencia, prefiriendo el oficio de periodista. 
¿Por qué clasificar a Goyo como perpetrador? Un asesinato político lo evidencia:

Uno de los tipos ya estaba montado en el Lada, y el otro, que estaba aún por ahí cerca y parecía nervioso, lo interrumpió.

-Déjalo ya, hombre. Con eso tiene. Un vergazo más y se puede morir. El hombre le soltó la camisa. El periodista quedó tendido de espaldas y pudo distinguir, un poco más lejos, el bigote hirsuto y la sonrisa. También pudo escuchar, aún mas lejos, el auto ya encendido $\mathrm{y}$ al otro hombre que gritaba.

- ¡Ahí déjalo, Goyo, vámonos! Lo último que vio José Ignacio Mejía fue la bota del hombre cuando venía a darle en la boca. (Aguirre, 2011, p. 208)

En el asesinato del periodista, previa paliza a patadas y palos (descrita de modo gráfico), vemos un claro acto de violencia política. Se relata que: "Luego lo hicieron rodar y empezó a sentir las patadas casi pulverizando sus costillas. Más tarde sintió el mismo golpe seco en la cabeza, solo que repetido varias veces con rapidez, con contundencia, con verdadera furia" (Aguirre, 2011, p. 207). Es ostensible el nivel meso de Gregorio, los otros policías secretos no tienen poder sobre él; Goyo se impone y da constancia de un fanatismo asesino.

También está en un nivel meso porque en diferentes partes de la obra se narra de fiestas donde concurre la alta dirigencia sandinista y los dos personajes centrales, dándose a entender su ubicación intermedia, pues solo mandos de tal calidad pueden acceder a ese tipo de contacto con las altas jerarquías del FSLN. Además, en la página 92 se narra que Gregorio depende de las órdenes de los jefes máximos del Estado sandinista, quienes aducen confiar en él, pero le advierten de la necesidad de ganársela cada día (Aguirre, 2011).

Pero los atroces crímenes políticos no son monopolio de la revolución una vez en el poder, sino inician en la etapa insurreccional. Un fragmento resulta esclarecedor:

La primera noche en El Dorado fue para mí inolvidable. En alguna casa de aquel barrio fue detectado y capturado un periodista fiel al somocismo que la población conocía como "el poeta carpintero", por sus versos, acrósticos y aforismos que lo congraciaban con el régimen y que hacía publicar en el diario Novedades, propiedad de la familia Somoza. El revuelo fue mayúsculo en aquella zona dominada por la guerrilla. Primero, el poeta fue identificado, después fue brevemente interrogado, y tras un juicio rápido bajo la presión de los combatientes que se ofrecian a lincharlo, decidieron fusilarlo. El pequeño pelotón atravesaba el parque. Hasta el sitio donde yo me encontraba podía escucharse la oración lastimera del condenado encomendándose al cielo; eran los últimos esfuerzos de un poeta cortesano que quizás nunca había matado a nadie, por lograr misericordia frente a una juventud enardecida y animada por supremos deseos de venganza. (Aguirre, 2011, p. 169, cursiva en el original) 
A las claras vemos el asesinato de un civil desarmado a cargo de una turba guerrillera. El asesinato de colegas una vez más constituye el pretexto para el crimen de un civil.

La violencia política se ejerce además contra un partido en formación, jefeado por Alfonso Robelo, quien organiza un evento en la ciudad de Nandaime, sofocado por la Juventud Sandinista, los Comités de Defensa de la Revolución y los grupos de choque (Aguirre, 2011). Se da cuenta de nuevas agresiones físicas y en grupo en contra de los opositores políticos del FSLN (ya en el poder): "Los apuntes de Gerardo dicen que la noche anterior se quemaron banderas del partido de Robelo y se atacó a golpes a quienes intentaron izarlas con la intención de animar a la gente para asistir el domingo a Nandaime" (Aguirre, 2011, p. 233). Se narran además el encarcelamiento de otro opositor, el sindicalista Huembes, y otra violencia:

Una fuerza de choque en ropa de civil se presenta al lugar y empieza la trifulca. Cuando llegan las patrullas la casa ya está en llamas, con toda la propaganda quemándose adentro. Aún quedaban algunas volantes en el Volkswagen de Huembes y también le dan fuego, con todo y el carro. (Aguirre, 2011, p. 235)

Vemos la forma de acallar toda alternativa al régimen de izquierda. Las violencias han ocurrido con el concurso de Gerardo, quien funge como perpetrador meso y ordena detenciones, ultrajes y seguimientos de opositores. Pero antes de los hechos de Nandaime había ocurrido un trabajo de espionaje por parte de Goyo, en contra de su propio amigo. En efecto en la página 230 se habla de que Goyo había espiado la oficina de Gerardo, husmeó furtivamente sus apuntes, para determinar "desviaciones políticas". Goyo lo insta a quemar un cuaderno secreto, a pesar de ser un texto apolítico cuyos temas versaban sobre fotografía, historia y cinematografía de Nicaragua.

En las páginas 232 y 233 se da fe de labores de espionaje ordenadas a Gerardo por sus jefes y en contra de la propia burocracia del régimen. Esta servidumbre autolesiva sin adecuaciones ni matices se asemeja a la definición de Montesquieu (2010) sobre el régimen despótico, en el cual: “...la índole misma del gobierno exige una obediencia extremada; una vez conocida la voluntad del príncipe, infaliblemente debe producir su efecto..." (Montesquieu, 2010, p. 27). Después, en ese contexto de demanda de lealtad, es mandatada la represión de Nandaime.

Pero hubo otro incidente de ataque físico masivo contra opositores. Se narra no de políticos, sino de un defensor de los derechos humanos a quien los críticos del régimen hacen un recibimiento en el aeropuerto, pero resulta frustrado a base de golpes por las fuerzas sandinistas (Aguirre, 2011). Así, de un allegado 
al sujeto se narra que: "El empresario radial fue el único del grupo de opositores que al final quedó atrapado entre la turba de sandinistas enfurecidos. Gregorio llegó hasta él y detuvo la golpiza" (Aguirre, 2011, p. 193). Pero Goyo no detiene las hostilidades sino para amenazar al hombre:

Gregorio le dio dos bofetadas y trató de entusiasmar a sus camaradas.

_ ¡A Abajo la burguesía! ¡Viva el poder popular! En medio de las respuestas eufóricas de aquella turbamulta, Goyo le advirtió al empresario que no debía seguir haciendo ese tipo de campaña; lo único que se ganaba con eso era el rechazo popular... Iba a dejarlo ir ahora, antes que llegara la policía, pero debía aprender la lección... (Aguirre, 2011, p. 194)

Deducimos un patrón reiterado de los sandinistas de utilizar la fuerza bruta y masiva para acallar toda idea contraria a sus principios y prácticas. Sin embargo, la vorágine de hostilidad arrastra también a los propios miembros del sandinismo.

Así, la zona gris incluye a integrantes del FSLN. La novela contiene un capítulo intitulado $X V$ La Virgen de Cuapa. Se narra el empleo de la sexualidad para el espionaje y el sabotaje, primero en el marco de la minoría homosexual, esto en las páginas 211 y 212 (Aguirre, 2011). A Goyo llega la historia de un militante católico de Cuapa que dice ver a la Virgen María en apariciones y moviliza personas con ese cometido. Sospechando del joven, Goyo le encarga la misión de comprobar el asunto a $\mathrm{Chu}$, un agente sandinista que es homosexual. Chu seduce al individuo y corrobora la sospecha de Goyo, y además graba todo en video. La grabación es usada luego por Goyo para chantajear y amenazar al joven católico con publicarla si sigue predicando (Aguirre, 2011). No se narra que Chu se inmute por el riesgo para él también de una eventual publicación del video, parece asumirlo a cuenta de ser pieza útil del FSLN. Por esto Chu forma parte de la zona gris.

Después se narra, con mayor detalle, el caso de Nelly, una mujer que tiene relaciones sexuales con un sacerdote opositor al régimen. Todo ocurre con el fin de sacarle información al religioso y al final hacerlo caer en el descrédito público, sacándolo del juego político. Máxime porque los mandos altos del FSLN le ordenaron a Goyo proceder con astucia en lo respectivo al clero, dado que el solo hecho de encarcelar a un sacerdote traía consigo presiones políticas contra el régimen (Aguirre, 2011). Nelly realiza este trabajo encubierto contra su voluntad:

Decile a Calaca, a Lenín o a quien sea, que yo no me vuelvo a acostar con ese hombre... Por un momento Goyo pensó que se trataba de uno más de aquellos típicos arrebatos histéricos que desde hacía algún tiempo se venían haciendo frecuentes y empezaban a fastidiarlo. Ya empezaba entonces a suspirar con paciencia, acomodándose en el sillón y disponiéndose como siempre a persuadirla. Incluso pensó - me dijo- en romper su propio récord y tratar de convencerla en menos tiempo que en ocasiones anteriores. Pero cuando 
ella por fin alzó la vista, viéndola a los ojos pudo darse cuenta de que esta vez no le serviría de nada el discurso del compromiso político, del sacrificio por el pueblo... Aquella mirada le confirmaba sin ninguna duda que, en efecto, esa había sido la última vez. (Aguirre, 2011, p. 210)

La mujer en realidad si accede luego a tener sexo con el cura, pero Goyo, haciéndose pasar por un marido celoso, irrumpe y da una golpiza al sacerdote (Aguirre, 2011). Hay presencia de la prensa y de manifestantes sandinistas (movilizados cerca para protestar contra la embajada de Honduras), pues todo era parte de una escena montada de previo (Aguirre, 2011). En medio del gentío irrumpe la trifulca: "Los periodistas llegaron cuando la golpiza estaba en su clímax. El cura, desnudo y con la nariz sangrando, le pedía a Goyo que lo dejara ir, por favor, pero Goyo lo seguía golpeando, dándole un festín a los camarógrafos" (Aguirre, 2011, p. 220). La prensa acomete presurosa al hecho: "El Vicario fue identificado inmediatamente por los reporteros, quienes empezaron a interrogarlo acerca de qué estaba haciendo ahí, y desnudo" (Aguirre, 2011, p. 220). Es Goyo quien responde a la pregunta: "- iSe estaba cogiendo a mi mujer, el muy hijo de puta!" (Aguirre, 2011, p. 220). De nuevo el FSLN, con Goyo como administrador de la violencia, ejerce su dominio sobre la población civil.

A todas luces Nelly forma parte de la zona gris, pues su jefe Goyo (cuyo carácter de perpetrador de nivel meso queda en evidencia) le impone sacrificar su subjetividad en aras del proyecto totalitario de los sandinistas. La fémina accede y con ello participa activamente de los actos brutales del régimen en contra del sacerdote involucrado. Nelly emplea su sexualidad con fines de dominación política, una forma de prostituirse a cambio de la causa sandinista.

Gregorio de nuevo aparece como un perpetrador de nivel meso, pues organiza violencias y dirige a subalternos. Pero ¿qué lugar ocupa Gerardo en la urdimbre del poder? Parece ubicarse a veces como perpetrador meso, pero más como un bystander, en términos de Critchell et. al. (2017). Porque participa en pocas acciones de ataques a civiles desarmados, y cuando acontecen agresiones masivas él no se suma, siendo más bien testigo (tercera parte).

No obstante, tampoco se exime de ser colaborador, porque sobre él se predica su trabajo en los departamentos de contrainteligencia, espiando a funcionarios, según se describió antes. Más aún, el ser bystander de ninguna manera exime de juicio ético, por cuanto ve violencias y no hace nada por frenarlas. Sin embargo, como veremos, esto cambia al final y en el desenlace Gerardo asume un papel crítico, causal a su vez de consecuencias.

Entonces, sintetizando los principales aspectos del nudo, los personajes, en especial Gregorio, resuelven los traumas de la guerra mediante una adhesión 
viciosa al FSLN y cometiendo crímenes para la perpetuación en el poder de dicho movimiento. Mediando escisiones del yo, Goyo emplea una hostilidad criminal y escoge siempre la vía de la violencia. Opera una ecuación en la cual todo opositor es igual a somocista o a miembro de la contra, en todo caso un enemigo que no merece misericordia. Sus supuestas fuentes son la propia institución de inteligencia del FSLN, por tanto, no hay control alguno en contra del aparato represivo ${ }^{12}$. Esa ausencia de piedad involucra también a los mismos integrantes del FSLN, zonas grises, simples objetos, y no sujetos del proyecto político izquierdista.

Finalmente, referimos el papel de los perpetradores macro, aunque se detalla más al final. Estos perpetradores son las altas jefaturas del FSLN, a quienes Goyo obedece. Aparecen poco en la mayor parte de la novela, básicamente en fiestas (que según se vio fungen para corroborar lealtades y afianzar militantes) o contratando a agentes medios. Sin embargo, su rol es clave. Con excepción de la Iglesia católica, y por cuestiones de juego político (presiones para no reprimirla), se carece de moderación alguna frente a la brutalidad de Gregorio. La jerarquía otorga patente de corso a Goyo para cometer cuanta ignominia desee y considere necesaria, todo para apuntalar la dominación del FSLN sobre Nicaragua. En un contexto de inquebrantables lealtades y un seguimiento forzoso de los mandatos, los grupos hegemónicos revolucionarios tienen un peso ético mayor en las atrocidades.

\subsection{La zona gris de los personajes principales y el culmen de la novela}

Un aspecto de suma relevancia es la diferencia entre Gregorio y Gerardo. Porque según se narra en la página 194, tras la golpiza al empresario radial, Goyo nota que su amigo flaquea y puede eventualmente desertar, de ahí que lo lleva a una fiesta con mandos medios y altos del FSLN (Aguirre, 2011). De esto se tiene:

Gregorio le dijo después a Gerardo (y eso me lo contó a mí también aquella noche de confesiones) que no se preocupara, que a él también lo asaltaba de vez en cuando la duda, pero entonces trataba de recordar lo que había costado todo aquello, y la necesidad de defenderlo. (Aguirre, 2011, p. 195)

Esta duda de la que se habla constituye un rasgo característico de Gerardo. Pero en vez de resolverla acudiendo a los muertos pasados para justificar nuevos crímenes, el individuo opta por la ambivalencia, no se suma de lleno a las

\footnotetext{
${ }^{12}$ Aquí vemos un orden político donde no existe un sistema de pesos y contrapesos según lo postula Montesquieu (2010), sino una dictadura despótica con poderes incuestionables.
} 
agresiones contra otros y piensa alternativas. Tal cosa contradice la lógica del régimen, donde el razonamiento autónomo se halla proscrito.

Así, el tema de la zona gris se comprueba con la prohibición de pensar, pues Gerardo y Goyo no pueden realizar ninguna crítica so pena de ser sometidos a castigo. No obstante, el primero empieza a dudar de la legitimidad y la coherencia del proyecto revolucionario, una vez consolidado. Así, Gerardo observa las enormes desigualdades de clase a lo interno del FSLN y en la narración se habla de cómo los altos jefes tienen mansiones y carros de lujo y sus esposas compran comida en tiendas de diplomático. Los altos dirigentes se convierten en clase dominante:

Cuando veía a sus mujeres pasear sin rubor en sus autos del año, escoltadas por humildes compañeros que ayudaban a cargar las compras de la tienda para diplomáticos. Compañeros que lucharon bajo las arengas de sus dirigentes contra las diferencias de clase, contra la injusticia social y el abismo ofensivo entre ricos y pobres; ahora convertidos en dóciles mayordomos de la vanguardia revolucionaria. (Aguirre, 2011, p. 235)

El cuestionamiento del personaje se hace expreso de forma estridente en el marco de una fiesta con los altos mandos sandinistas, acusándolos de cipayos, el personaje espeta que:

Ya habían olvidado el valor con que se enfrentaron a la guardia de Somoza y ahora no se atrevían a protestar por el derroche y el hedonismo con que se conducían sus dirigentes, mientras la mayoría de la población soportaba las privaciones y entregaba a sus mejores hijos para ir a combatir a la frontera. (Aguirre, 2011, p. 238)

Luego, las acusaciones se hacen más contundentes. Ante el cuadro, los mandos altos lo mandan a la cárcel por veinte días y le abren un proceso, instándole a reconocer que todo fue producto de la borrachera (Aguirre, 2011). El sujeto se niega, entonces:

Por eso, cuando le pidieron que contestara, cuando le dijeron que reconociera que sólo había sido un exabrupto, locuras de borracho, se levantó de su asiento y pidió su renuncia. A la semana siguiente fue expulsado del partido y fue dado de baja en vigilancia estricta. (Aguirre, 2011, p. 239)

Este castigo se origina en la crítica, ejercida por Gerardo en virtud de la duda. Él no llama a ser esclavos de la historia, la duda puede verse como defensa de la subjetividad. Esto puede entenderse en clave existencialista. De tal manera: "Pero el hombre, en su rebeldía, fija a su vez un límite a la historia. En este límite nace la promesa de un valor" (Camus, 2008, p. 289). Vemos un posicionamiento existencial, a su vez con repercusiones políticas: "Es el nacimiento de este valor el que, hoy día, combate implacablemente la revolución cesárea, porque representa su verdadera derrota y la obligación para ella de renunciar a sus principios" 
(Camus, 2008, pp. 289-290). La revolución reclama y necesita fidelidad total, el sujeto estorba. En la novela lo dicho se cristaliza en los aparatos del régimen, que exigen una lealtad absoluta. La obra expone como Goyo fue andamio, y no sujeto del sandinismo:

No ha pasado mucho tiempo desde que Gerardo lo vio llorar por primera vez. Era como el llanto de un niño rebotando en las sucias paredes de la celda. Un niño a quien los mayores del grupo ya no dejan participar en el juego y más que los golpes o los coscorrones le duele sentirse impotente y humillado. Él, que ya había aprendido el secreto para codearse con los grandulones, ahora estaba fuera; él, que en el último momento se negó a ser un delator, se sintió al final delatado. Y Gerardo fue el único que lo vio llorar en su celda, el único a quien el gran Gregorio Suárez permitió un instante de compasión. Porque con el llanto de Gregorio se perderían para siempre las imágenes de un tiempo en el cual llegó a sentirse poderoso, dueño de vidas y muertes... (Aguirre, 2011, p. 16)

Este fragmento demuestra la ruina final del personaje, que debe ser explicada. Con la derrota del FSLN en las urnas en 1990, los compañeros de Goyo fueron despedidos, después él afrontaría igual suerte, ayudando declaraciones que él dio a una periodista extranjera tiempo antes, donde opinó en contra de altos mandos sandinistas (Aguirre, 2011). El agente cae en desgracia no por sus crímenes, sino merced a negociaciones y componendas políticas.

Porque comprobamos, desde el análisis de una obra ficcional, lo dicho por Nygren (2003) sobre Nicaragua: no hubo procesos de reparación ni de justicia; por tanto, las violencias siguieron ${ }^{13}$. Así, en el marco de la novela, los mandos altos del FSLN optaron primero por quemar toda la información comprometedora, y luego por sacrificar a sus zonas grises. Al respecto, los sandinistas de mayor rango buscaron dar la impresión de que eran de confianza en el marco del nuevo régimen democrático, para así permanecer en puestos de confort. En consecuencia, un primer movimiento fue delatar a los antiguos integrantes, perpetradores meso, como Goyo, quienes tenían arsenales para protección personal (Aguirre, 2011). En la página 261 de la novela, los sandinistas aún en puestos de importancia enviaron patrullas para que decomisaran el arsenal de Goyo, quien, aunque pudo librarse de cargos judiciales, fue despedido. Y ese era solo un primer paso de una táctica demoledora.

Gregorio recibe, al final de la novela, un engaño mayúsculo cuando un agente encubierto, al servicio de sus antiguos jefes (reinstalados en el Estado

\footnotetext{
${ }^{13}$ Sobra decir que en la actualidad el FSLN volvió a instituirse como dictadura y ha ocasionado, en poco tiempo, cientos de asesinatos políticos contra civiles y el éxodo masivo de personas, de modo directo, por no hablar de un manejo del coronavirus que revela un nulo interés de auxiliar a la propia población de Nicaragua. Sobre la crisis de Nicaragua, Amnistía Internacional (2018) habla de torturas, de asesinatos extrajudiciales y de otras acciones graves de violencia política.
} 
supuestamente democrático posterior a 1990) le propone atentar contra la vida del presidente electo, Arnoldo Alemán (Aguirre, 2011, pp. 287-288). Goyo se arma con una pistola y TNT para asesinar al hombre, pero tiempo antes del atentado la policía lo atrapa, con conocimiento completo del plan. Termina en la cárcel, temiendo por su vida (quizás la venganza de los familiares de alguna de sus tantas víctimas o de un ex contra) (Aguirre, 2011).

Gerardo, quien más que perpetrador fue un bystander, siempre dubitativo y poco afecto a la violencia, culmina la obra como periodista político, luego de ser dado de baja de la institución. En apariencia, el narrador busca exonerar de una ruina total a aquellos cuya violencia fue menor, o para decirlo de forma patente, no cometieron homicidios. Dicho sea de paso, en la obra Nelly se separa de su marido (el Negro Heller), quien la echa de casa por infiel, pero no sufre de cárcel ni de muerte.

Vemos entonces el desenlace de la novela. Los perpetradores macro cometen su último acto en contra de los perpetradores meso, zonas grises a toda luz. Y también realizan un crimen mayúsculo: la quema de los documentos con todas las pruebas de las represiones, espionajes y asesinatos, con lo cual Nicaragua no puede tener procesos de reparación ni de justicia. Así, una parte de los perpetradores, los macro, sale incólume, y la otra, los meso, termina en la ruina o en posiciones un poco menos desventajosas.

Retomando lo implícito, tenemos otros elementos para apoyar la hipótesis de los perpetradores en tanto nudo. Porque en efecto, el grueso del texto trata o de represión violenta, o de urdimbres políticas que tarde o temprano decantan en esto. Se refiere la guerra abierta contra la contra, y la Guerra Fría (apoyo a la guerrilla salvadoreña, contribución de Cuba con el FSLN, y enemistad con Estados Unidos), pero representan temas secundarios. Salvo francas excepciones (cooperativas agrarias y campaña de alfabetización), ni las altas jerarquías, ni Goyo, ni Gerardo hablan de políticas sociales o laborales.

Y según se vio, las desigualdades de clase continúan, siendo el único cambio los rostros de los sectores hegemónicos. A todas luces el leitmotiv de los sandinistas es la violencia y el odio entre sectores políticos, no la mejora de la calidad de vida de los estratos populares, ni tampoco lo que teóricos de izquierdas alternativas denominan como la "revolución social"14. A los relatos de la

\footnotetext{
${ }^{14}$ Sobre esto hay debates. Los marxistas no adscritos al marxismo-leninismo ni a las izquierdas pro-Cuba suelen achacar la ocurrencia de dictaduras de izquierda a proyectos que no siguen el marxismo original. Esos proyectos encumbrarían a una clase burocrática, responsable de los crímenes y de dominar a los sectores subalternos por ser la burocracia la nueva clase explotadora. Sin embargo, desde el pensamiento liberal se argumenta por otra línea. Se aduce que al concentrarse el poder en pocas manos y al carecerse del sistema democrático de pesos y contrapesos (prensa
} 
fastuosidad y la riqueza de los comandantes principales se suma la incorporación de sandinistas a la empresa privada, de lo cual da cuenta Gerardo en su relato de la página 46 (Aguirre, 2011). A las claras, se trata de un proceso revolucionario en su sentido de conflagración, pero no de cambio social, pues todos los patrones de clase y hegemonía política sobreviven.

La brutalidad de Somoza es reeditada por el FSLN, partido que, merced a los traumas de los sujetos y del manejo antiético que éstos hacen de su situación, saca provecho y proyecta a estas personas para que acaben con toda disidencia. De tal forma, los jefes del sandinismo se perpetúan en el poder gracias a la sangre derramada por otros en ciudades y campos de batalla, mientras ellos llevan vidas de lujos. Dicho de otra forma, el sandinismo construye de modo constante enemigos totales en las figuras de los disidentes, y canaliza en su contra el odio y el resentimiento de los sujetos en cuestión.

El motor del proceso reside en ser perpetradores en contra de todos los opositores políticos, a quienes se asesina, golpea y persigue tras endosarles categorías equivalentes a un "mal absoluto" ("contras", "burgueses" y "somocistas"). $\mathrm{Y}$ en la cima de estos criminales se haya los altos mandos, cuyo dios no es otro que el poder. Porque no vacilan en pactar con sus antiguos enemigos y entregarles a los perpetradores meso, todo para acomodarse al nuevo Estado y seguir siendo hegemonía social.

\section{CONCLUSIONES}

La novela Con sangre de hermanos se estructura con base en una dialéctica de víctima y perpetrador. Los personajes principales son al principio objeto de intensas violencias políticas, siendo posible caracterizarlos como sobrevivientes de carácter inmediato, con una situación emocional comprometida en virtud de las experiencias traumáticas.

\footnotetext{
independiente, separación de poderes, partidos de oposición, elecciones libres, etc.) se genera una dictadura, con todos los ultrajes y brutalidades concomitantes. Por esto las revoluciones tan a menudo degeneran en gobiernos dictatoriales, independientemente de qué modelo marxista digan seguir. Cuando se abandera una visión de mundo como la única válida, un grupo político se autoproclama portador absoluto de la verdad, y en consecuencia se divide la sociedad en un bando de leales y otro de disidentes contra quienes resulta admisible toda violencia, se está a las puertas del totalitarismo, sin importar si los perpetradores son un dictador y su pequeño grupo, o bien un partido "de amplia base". Clásicos como Locke (2005) habían advertido del gobierno despótico, aquel donde el gobernante se coloca por encima de la ley, dado esto dispone a su antojo de las vidas y las libertades de los ciudadanos, quienes pasan a vivir en esclavitud. Por su parte Arendt, Camus y MerleauPonty argumentaron críticamente acerca de los rasgos profundamente totalitarios del comunismo, esto por no referir la radical crítica de Hayek y Mises a dicha ideología y práctica política.
} 
Siguiendo una misma línea argumentativa, la muerte de colegas y procesos divisivos en el self inciden en los personajes. Estos hacen un manejo de su estado emocional y de sus experiencias para devenir en perpetradores y justificar toda clase de agresiones masivas contra población civil, siendo relativa excepción Gerardo en tanto se ubica más como bystander. Lo anterior se construye en torno a un esquema en el cual todo opositor al FSLN equivale per se a somocista, contra y asesino, siendo objeto de abyectas persecuciones y crímenes. El carácter sacrificial del movimiento sandinista queda descubierto también a lo interno, con políticas de zona gris para sus integrantes, donde éstos renuncian a su dignidad y su libertad para contribuir con el dominio del sandinismo.

Vemos que en efecto la novela se estructura en una dialéctica víctimaperpetrador. En esta vorágine de víctimas y victimarios, los mandos altos del FSLN imponen su ley. Cual moderno Huitzilopochtli, el gobierno revolucionario exige un tributo de sangre, y también lealtad absoluta. Lejos de ser un proyecto en beneficio de los pobres, en realidad los hechos apuntan a una nueva clase dirigente, que para mantenerse en el poder borra primero las huellas de sus crímenes (los archivos de la inteligencia sandinista) y se deshace de sus cuadros medios, los cuales pasan a ser victimas (zonas grises). Así, la novela cierra con la derrota total de quienes dijeron creer en la justicia, pero practicaron la brutalidad y los ultrajes contra terceros, y terminaron apuntalando a un FSLN claramente idéntico a la represión asesina de Somoza.

\section{BIBLIOGRAFÍA}

Aguirre, E. (2011). Con sangre de hermanos. Uruk Editores.

Amnistía Internacional. (2018). Sembrando el terror: de la letalidad a la persecución en Nicaragua. https://www.amnesty.org/download/Documents/AMR4392132018SPANISH.PDF

Aristóteles (1999). Poética (V. García, trad.). Gredos.

Bothmann, A. (2015). Transitional Justice in Nicaragua 1990-2012. Drawing a Line Under the Past. Springer VS. https://doi.org/10.1007/978-3-658-10503-7

Bouwknegt, T. B. (2017). Duch Is Dead. Book review: Alexander Laban Hinton, Man or Monster? The Trial of a Khmer Rouge Torturer (Durham \& London: Duke University Press, 2016). Journal of Perpetrator Research, 1(1), 110-114. https://doi.org/10.21039/jpr.v1i1.42

Camus, A. (2008). El hombre rebelde. Alianza Editorial.

Critchell, K., Knittel, S., Perra, E., \& Ümit Üngör, U. (2017). Editors' Introduction. Journal of Perpetrator Research, 1(1), 1-27. https://doi.org/10.21039/jpr.v1i1.51 
Esparza, M. (2018). Examining the Political and Military Power in Latin America: A Response to Christian Gudehus. Journal of Perpetrator Research, 2(1), 20-25. https://doi.org/10.5334/jpr.2.1.9

Hatcher, R. (2018). The Power of Memory and Violence in Central America. Springer International Publishing. https://doi.org/10.1007/978-3-319-89785-1

Hinton, A. L. (2016). Man or Monster? - The Trial of a Khmer Rouge Torturer. Duke University Press.

Levi, P. (1989). The drowned and the saved. Vintage International.

Lifton, R. (2005). Americans as Survivors. The New England Journal of Medicine, 352(22), 2263-2265.

Lifton, R. (2006, 14 de junio). Haditha: In an 'Atrocity-Producing Situation' — Who Is to Blame? Editor \& Publisher Magazine. https://www.editorandpublisher.com/stories/haditha-in-anatrocity-producing-situation-who-is-to-blame, 80313 ?

Locke, J. (2005). (C. Amor \& P. Stafforini, trad.). Ensayo sobre el gobierno civil. Universidad Nacional de Quilmes y Prometeo Libros.

Maringira, G. (2016). Political violence within army barracks: desertion and loss among exiled Zimbabwean soldiers in South Africa. Social Dynamics, 42(3), 429-442. https://doi.org/10.1080/02533952.2016.1238390

Merleau-Ponty, M. (1957). Las aventuras de la dialéctica. (J. Escudé, trad.). Ediciones Leviatán.

Montesquieu, C. (2010). Del espiritu de las leyes. Editorial Porrúa.

Morag, R. (2013). Waltzing with Bashir: Perpetrator Trauma and Cinema. I.B. Tauris.

Morag, R. (2018). On the Definition of the Perpetrator: From the Twentieth to the Twenty-First Century. Journal of Perpetrator Research 2(1), 13-19. https://doi.org/10.5334/jpr.2.1.19

Nygren, A. (2003). Violent conflicts and threatened lives: Nicaraguan experiences of wartime displacement and postwar distress. Journal of Latin American Studies, 35(2), 367-393. https://doi.org/10.1017/S0022216X03006758 
